\title{
ARGUMENTAÇÃO, CAPACIDADE CIVIL E DISCERNIMENTO: A INTERPRETAÇÃO POSSÍVEL APÓS O ESTATUTO DA PESSOA COM DEFICIÊNCIA
}

\section{${ }^{1}$ Maria Cláudia Mércio Cachapuz}

\section{RESUMO}

Discussão sobre o conceito de autonomia em conflitos jurídicos complexos, como na definição da capacidade civil pela Lei $\mathrm{n}^{\circ}$ 13.146/15. Debate sobre a medida de estabelecimento de limite a priori a um exercício de liberdade e da forma como devem estar justificada qualquer restrição de liberdade, ao mesmo tempo em que se potencializa a autonomia como um princípio relevante à construção da moral na sociedade contemporânea. Propõe questionamento à edição recente do Estatuto da Pessoa com Deficiência no Brasil por suprimir os incisos do art. $3^{\circ}$ do Código Civil brasileiro.

Palavras-chave: Direito civil, Argumentação, Capacidade civil, Discernimento

\section{LA ARGUMENTACIÓN, CAPACIDAD CIVIL Y CONOCIMIENTO: LA INTERPRETACIÓN POSIBLE DESPUÉS DE LA LEY DE LA PESONA CON DISCAPACIDAD}

\section{RESUMEN}

Este trabajo discute el concepto de autonomía en conflictos legales complejos, como se ha visto en la definición de la capacidad civil por la reciente promulgación de la Ley $\mathrm{n}^{\circ} 13.146$ 15. Debate el establecimiento de límites a priori al ejercicio de libertades y de cómo debe justificarse por serias razones la restrición a cualquier libertad, mientras si expande la autonomía como un principio a la construcción de la moral en la sociedad contemporânea. Propuesta de discusión acerca de la supresión de los parágrafos del artículo $3^{\circ}$ del Código Civil brasileño.

Palabras-clave: Derecho civil, Argumentación, Capacidad civil, Conocimiento

\footnotetext{
1 Doutorado em Direito pela Universidade Federal do Rio Grande do Sul - UFRGS, Rio Grande do Sul (Brasil). Professora do Mestrado em Direito e Sociedade pelo Centro Universitário La Salle - Canoas - UNILASALLE, Rio Grande do Sul (Brasil). E-mail: mcmcachapuz@tj.rs.gov.br
} 


\section{INTRODUÇÃO}

Quando, com muita propriedade, Luc Ferry escreveu que "cada colega é, por definição, um sujeito que `supostamente sabe” (FERRY, 2011, p. 11), buscando demonstrar que talvez tenha que se ter a humildade necessária para reconhecer as diferenças de compreensão sobre assuntos diversos aos de nossa especialidade, restou acentuado o quanto de dificuldade há para integrar temas acadêmicos afins que exigem um universo de conhecimento bastante específico. O que quer dizer que, por vezes, aventurar-se, por necessidade, numa seara acadêmica diversa à própria ou que exija conhecimentos de áreas afins - e para as quais exista uma estrutura de conceitos previamente conhecidos - torna-se imprescindível buscar aprofundar a troca de experiências de forma interdisciplinar, seja para tornar acessíveis as informações que são pretendidas sem a necessidade de novo esgotamento da matéria, seja para efetuar o teste daquilo que é conhecido frente à realidade do outro - ou do que é de conhecimento do outro. É o que permite, efetivamente, a construção de uma gênese crítica (ALEXY, 2012, p. 153), pela qual se torna possível reestruturar e atualizar categoriais jurídicas a partir de novas realidades empíricas que se tornem evidenciadas.

De fato, é relativamente cômodo enfrentar o problema novo que se impõe em sociedade - e que permite repercussões jurídicas relevantes - a partir da alteração normativa de estruturas dogmáticas a respeito da definição jurídica sobre a capacidade humana. Portanto, supostamente exigindo-se do intérprete que apenas efetue um movimento de simples subsunção da particularidade à situação genérica previamente estabelecida na regra jurídica. Ou, talvez de forma ainda mais arbitrária, que, na ausência de regramento específico ou na revogação de restrições que já existam, que se permita criar, desde logo, categorias ou modelos gerais de enfrentamento do fenômeno desconhecido, como que reconhecendo uma vitória permanente do empirismo sobre o que seja dogmático. Num ou noutro caso, o movimento de interpretação se traduz num descuido acadêmico relevante, afastando-se da pretensão de produção de efetivo conhecimento científico.

$\mathrm{O}$ que se tornar relevante, portanto, ao verificar-se a supressão normativa dos incisos I a III do art. $3^{\circ}$ do Código Civil brasileiro, que tratam da capacidade de pessoas com deficiência, em face da publicação da Lei no $13.146 / 15$, é estabelecer-se o debate acerca da alteração dogmática fomentada para o instituto da capacidade civil, especialmente em face da automática retirada do conceito de "discernimento" como balizador ao exame da manifestação livre da vontade humana. O que se propõe é, numa análise jurídico-filosófica, testar-se em que medida tal supressão contribui, ou não, para a construção de respostas 
corretas do ponto de vista jurídico e com que extensão pode ser verificada, para as situações concretas de análise do problema, maior instabilidade ou discricionariedade na tomada de decisões judiciais. E veja-se: Ao ser estabelecido um debate como este em que a ótica de compreensão dos temas, ao fundo, é jurídica, não raro é possível identificar-se, no enfrentamento dos assuntos propostos, diferenças fundamentais de compreensão dos fenômenos sociais. Principalmente, no que se refere à dimensão filosófico-jurídica de análise, por pressupor visões também diversas do próprio fenômeno jurídico num caráter geral.

Assim é que a discussão ora proposta sobre o tema relativo à capacidade jurídica frente à edição do Estatuto da Pessoa com Deficiência, especialmente em face de leituras promovidas em grupo de estudos ${ }^{1}$ sobre Martha Nussbaum (2013) e Jürgen Habermas (2004) - portanto, partindo-se de visões diversas sobre a definição da razão empírica pressuposta (HABERMAS, 1991, p. 81) -, busca evidenciar-se enfoques, distintos e complementares, da questão, a partir de visões igualmente críticas do ordenamento jurídico.

Numa primeira parte deste ensaio, à luz de uma compreensão mais teórica e genérica do problema posto, há o enfrentamento da contribuição da Filosofia contemporânea para a construção de categorias jurídicas concernentes à personalidade e à capacidade, a partir de conceitos de liberdade e responsabilidade, discutindo-se as questões de construção dos juízos por critérios não deterministas ou naturalistas. Uma apreciação que exige o enfrentamento do tema do individualismo moderno e da compreensão de inclusão do outro como traço de humanidade para a superação dos paradigmas tradicionais do Direito. Num segundo momento, por meio do exercício de teste da normatividade oferecida pela edição da Lei $\mathrm{n}^{\mathrm{o}} 13.146 / 15$, a pretensão é de análise dogmático-jurídica do instituto da capacidade civil, especialmente para construir alternativas sólidas de formação do juízo ao intérprete jurídico frente às situações concretas que possam ser oferecidas a julgamento.

A ideia é a de fomentar o debate, a partir de estruturas conhecidas - a capacidade jurídica -, para um tema que se apresenta como bastante contemporâneo em sociedade - a autonomia de julgamento a pessoas com deficiência e a promoção de um princípio de igualdade jurídica, em seu aspectos formal e material. Um debate que, ao fundo, suscita discussões preliminares conhecidas do mundo acadêmico, como a questão da oposição entre

\footnotetext{
${ }^{1}$ Especificamente, a referência ao trabalho de pesquisa desenvolvido no grupo de estudos sobre Direito, Meio Ambiente e Novas Tercnologias do Mestrado em Direito e Sociedade do Unilasalle.

${ }^{2}$ Como bem esclarece Luc Ferry, "a simpatia não é senão um fato que se choca contra outros fatos e, como tal, nada justifica: há os que amam a tourada de facto, os que a reprovam de facto e, caso se
} 
determinismo e cultura ou o problema da codificação e dos fenômenos pertinentes a direitos de personalidade. Nem por isso, contudo, há como se deixar de enfrentar o tema. Existe, aqui, pressuposta uma discussão sobre as diferenças e igualdades em sociedade, sobre partilhas de espaços de poder e convivência, sobre liberdades e instintos de sobrevivência. Análises que, mesmo quando propostas para o debate por uma única espécie animal - o homem -, não descartam reflexos em outras discussões passíveis de estudo - como na análise da capacidade de animais não-humanos, ainda que tal estudo demande outras categorias de enfrentamento da questão -, seja porque pressuponha o reconhecimento genuíno de uma igualdade de direitos, seja pela identificação de uma necessidade mútua de convivência das pessoas em sociedade.

Nessa medida é que o debate é proposto. Como meio de fomentar, a partir de argumentos sérios e suficientes, a construção de categorias civis sólidas ao enfrentamento das questões sobre personalidade e capacidade a pessoas com deficiência. Uma discussão que, uma vez proposta, não pretende encerrar o tema, mas apenas abri-lo para a compreensão do intérprete jurídico, permitindo novos diálogos acadêmicos.

\section{PARTE I: A LEGITIMAÇÃO DA CAPACIDADE A PARTIR DO RECONHECIMENTO DO OUTRO}

Quando aqui se busca trabalhar estruturas da modernidade, como o problema da capacidade jurídica, por meio de uma discussão nova - o alcance desta capacidade a partir de pressupostos de igualdade jurídica -, imprescindível que se tenha por começo um debate sobre a própria possibilidade deste alcance a partir das categorias atuais disponíveis ao estudo de uma alteração de paradigma. Porque aqui, ao fundo, o que se está a discutir é quanto à efetiva possibilidade, no mundo contemporâneo, de reconhecer-se capacidade ampla ao indivíduo a partir de estruturas fundadas no reconhecimento de uma igualdade formal e material a priori, portanto, pressuposta abstratamente. De certa forma, partindo-se de onde Sérgio Paulo Rouanet, no seu Mal-Estar da Modernidade (1998) lançou o debate “(...) salvo mutações genéticas inesperadas, homens e mulheres continuarão tendo uma anatomia própria. As epidermes continuarão sendo brancas e pretas e as tradições culturais serão mantidas em sua variedade. O Ilumisnismo não exclui a diferença, mas exclui a diferença como ideologia" (ROUANET, 1998, p. 69) -, busca-se identificar qual possibilidade existe, a partir de uma ética universal, cara à modernidade, de discutir-se a possibilidade de relativização do próprio conceito de sujeito de direito como centro da avaliação do ordenamento jurídico a partir de um conceito de racionalidade pressuposto, de 
forma que o estatuto da capacidade seja aberto a uma diversidade não apenas cultural - no âmbito antropológico da discussão proposta e ainda nem bem resolvida por uma ética aplicada -, mas também biológica e genérica da própria espécie. Por isso o tema não escapou a Luc Ferry quando tratou do problema do ecofeminismo ou do elogio à diferença (FERRY, 2009), justamente como forma de abordar as dificuldades de tratamento da matéria sobre a diversidade entre humanos: "Ele" (o tema) "é onipresente nas universidades, onde contribui poderosamente para fazer reinar o terror intelectual exercido em nome do 'politicamente correto' e do direito à diferença que se estende facilmente pela reivindicação de uma diferença de direitos" (FERRY, 2009, p. 205).

Daí a dificuldade: Nem bem resolvemos, no âmbito social da modernidade, o problema das diferenças entre seres humanos e queremos resolver inclusive o problema da diversidade entre as espécies - o que permite um debate próprio, ainda que afim, sobre a capacidade de animais não-humanos -, justamente, para universalizar conceitos criados em torno da capacidade do indivíduo e a partir de uma característica considerada primordial aos modernos à distinção da espécie, a razão. E aqui, portanto, a discussão não se baseia na criação de uma proteção jurídica aos considerados incapazes - o que, ao menos do ponto de vista formal, já existe -, mas em discutir o próprio pressuposto da situação de capacidade abstrata considerada, fundada em posições jurídicas predeterminadas e ora desafiadas em face da edição do Estatuto da Pessoa com Deficiência. Situação que, a partir de uma distinção legislativa, busca identificar na diferença de constituição de características físicas e intelectuais dos indivíduos esta "diferença de direitos", cunhada por Luc Ferry (2009, p. 205), capaz de universalizar, pela própria distinção efetuada em abstrato, a procura por uma igualdade material através de estatutos jurídicos próprios.

A complexidade de abordagem da matéria, portanto, não pode estar fundada na simples simpatia que se possa desenvolver pelo tema da igualdade jurídica ${ }^{2}$. É preciso um esforço superior do intérprete jurídico para vencer o problema da diferença entre os indivíduos, uma vez que não se trata, unicamente, de um problema de identificação do traço distintivo da razão entre as pessoas, e sim, da medida de real proteção pretendida em abstrato para que se permita, efetivamente, ver identificada uma situação de ausência de

\footnotetext{
${ }^{2}$ Como bem esclarece Luc Ferry, "a simpatia não é senão um fato que se choca contra outros fatos e, como tal, nada justifica: há os que amam a tourada de facto, os que a reprovam de facto e, caso se queira decidir de jure, será preciso se elevar apenas acima da esfera do factual para buscar argumentos (FERRY, 2009, p. 236).
} 
distinção jurídica - para fins de tutela - em face da diferença. Circunstância jurídica que permite, pela extensão e estabilização do argumento, que se avance o exame do tema da distinção entre os seres em razão da racionalidade, inclusive, para o debate sobre a capacidade dos animais não-humanos - seara de discussão, contudo, que impõe trabalho próprio de enfrentamento jurídico.

Para iniciar-se o debate sobre o tema da capacidade, é fundamental que se analise o problema da racionalidade para os modernos, na medida em que se trata de uma circunstância cara à distinção entre os seres. Ainda que se possa identificar, biologicamente, pelo exercício da experimentação empírica, traços racionais - ou mesmo de escolha livre inclusive ao animal não-humano, a dificuldade de estender-se estatutos jurídicos próprios à humanidade - portanto, que estejam ligados ao conceito de pessoa - ao animal não-humano traduz-se numa barreira até o momento intransponível a partir da ótica da modernidade. E explica-se. É que ainda não se consegue vencer, em relação a outras espécies de animais, o problema intrínseco da natureza em relação à sua determinação sobre a condição instintiva. Ou seja, a possibilidade de que, principalmente em situações extremas ou de efetiva escolha entre espécies, haja alteridade para uma escolha ou mesmo um julgamento justo, que possa importar, inclusive, em restrições efetivas à própria espécie em benefício de outra, justamente porque possível a compreensão de que necessária se apresenta uma sobrevivência universal. Este caráter de universalidade, para além da própria espécie, é que permanece como um traço distintivo da capacidade humana de determinação em relação aos demais animais.

Há, no entanto, que se ponderar quanto a esta intervenção qualificada do ser humano sobre a natureza. Aqui não se está a defender o fato de que o ser humano efetue este controle sobre a natureza das espécies com maestria - há, ao contrário, exemplos suficientemente caracterizadores de sua capacidade destrutiva. O que se pondera, a partir de categorias universais, é o argumento pertinente à distinção do traço de humanidade na sociedade moderna. Ao menos, para afastar, até a geração de novos paradigmas, a alteração de estatutos jurídicos tão caros como o da capacidade jurídica. E nisso alguns conceitos modernos de liberdade se configuram como necessários para melhor explicarem a defesa de tal ponto de vista, com repercussões a serem consideradas na segunda parte deste ensaio em relação ao tema do "discernimento".

É que ao centro da discussão sobre um alargamento da ideia de humanidade em relação a animais não humanos - ou das prerrogativas jurídicas que encerra - está predisposto o debate do quanto é possível se reconhecer autonomia aos seres, de forma que 
possam alcançar e desenvolver efetiva capacidade como sujeitos de direitos. Um reconhecimento que não se esgota na proteção ao meio ambiente e aos animais de uma forma ainda mais específica, mas que busca identificar se é possível falar-se no respeito a uma liberdade subjetiva própria, porque identificada uma autonomia como ente próprio. E, portanto, como alguém capaz de participar de um diálogo jurídico, como destaca Habermas, "voltado para o consenso que somos chamados a exercer a virtude cognitiva da empatia em relação às nossas diferenças recíprocas na percepção de uma mesma situação" (HABERMAS, 2004, p. 10). Essa é que parece ser a chave à discussão do problema. Ou seja, se é possível, pela experiência científica contemporânea, reconhecer aos seres de uma forma ampla, por identificar-lhe aspectos cognitivos, sensitivos e culturais complexos - que possam, inclusive, transcender à simples condição extintiva de sobrevivência -, a qualidade de participante de um discurso jurídico com a autonomia necessária ao reconhecimento de uma capacidade jurídica própria, independentemente da representação por terceiros. Por isso, fundamental que se tenha esclarecido, previamente, o alcance de conceitos como os de autonomia e liberdade subjetiva.

Habermas, com muita propriedade, estabelece uma distinção inequívoca: os conceitos se diferenciam pelo âmbito de sua abrangência. Enquanto a liberdade é sempre subjetiva, porque fundada nas peculiaridades do indivíduo - suas "máximas de prudência, pelas preferências ou motivos racionais" (HABERMAS, 2004, p. 12) -, a autonomia é um conceito que pressupõe intersubjetividade, determinado por máximas aprovadas pelo teste da universalização.

Quanto à liberdade subjetiva, não é difícil imaginar que algumas pessoas possam gozar da
liberdade e outras não, ou que algumas pessoas possam ser mais livres do que outras. A
autonomia, ao contrário, não é um conceito distributivo e não pode ser alcançada
individualmente. Nesse sentido enfático, uma pessoa só pode ser livre se todas as demais o
forem igualmente. A ideia que quero sublinhar é a seguinte: com sua noção de autonomia
Kant já introduz um conceito que só pode explicitar-se plenamente dentro de uma estrutura
intersubjetivista. (HABERMAS, 2004, p. 13) Isso significa compreender que - para efeito de participação num discurso jurídico, que essencialmente trabalha com categorias morais - ainda que se possa reconhecer a liberdade num âmbito próprio ao animal não-humano, por identificar-lhe capacidade e racionalidade específicas, é necessário que lhe seja possível visualizar também autonomia em potencial, porque autorizada, a qualquer ser - portanto, numa concepção mais ampla que a ideia de indivíduo -, a percepção de participante de uma comunidade moral, "como uma comunidade formada de indivíduos livres e iguais que se sentem obrigados a tratar uns aos 
outros como fins em si mesmos" (HABERMAS, 2004, p. 13). Participar do discurso jurídico não importa, portanto, em simples verificação de uma potencial liberdade em sociedade, pelas escolhas realizadas pelo ser. É preciso que se reconheça autonomia ao ser, porque, no mínimo, ao menos em potencial, há o reconhecimento intersubjetivo - ou, talvez, interespécies - de que tratamos, uns aos outros - e, portanto, interespécies - como fins em si mesmos. Enquanto não restar identificado em outra espécie animal esta capacidade de universalização que é desenvolvida pela razão qualificada do homem, toda e qualquer autonomia que se confira a qualquer um por meio de uma capacidade jurídica será meramente falaciosa.

E, veja-se. Com isso não se quer afirmar que o homem consiga desenvolver esta habilidade da autonomia de forma desinteressada. Ao contrário, a própria história da humanidade revela os traços de profunda dificuldade na aceitação do outro, da liberdade do outro, da soberania do outro. Isso, contudo, não retira do ser humano a sua qualidade como ser autônomo, porque potencialmente se lhe reconhece a capacidade de transcender à própria individualidade para alcançar a sobrevivência do outro em sociedade. E o que é relevante: do outro que, necessariamente, possa nem ser da mesma espécie.

Os participantes, no momento mesmo que aceitam uma tal prática argumentativa, têm de estar dispostos a atender à exigência de cooperar uns com os outros; e, mais ainda, têm de estar dispostos a deixar-se afetar e motivar, em suas decisões afirmativas e negativas, por essas razões e somente por elas. (HABERMAS, 2004, p. 15)

Tal argumentação, de certa forma, põe em destaque a situação crítica do pensamento moderno quanto ao problema da reciprocidade e a medida de reconhecimento de tal condição em termos jurídicos. Ou seja, em que medida o argumento da distinção entre seres por meio da racionalidade atrapalha a possibilidade de construção de estruturas efetivamente igualitárias entre os indivíduos que possam ser identificados por diferenças de compreensão cognitiva. Situação apontada por Nussbaum como central ao problema de construção de estruturas contemporâneas à capacidade em termo de igualdade entre os indivíduos:

De fato, pessoas com impedimentos mentais graves parecem ser aqueles "poucos indivíduos" que, carecendo das faculdades morais em um nível mínimo essencial, fracassam em se qualificar para a igualdade. Mais ainda, da mesma forma que Kant e Rawls negam explicitamente que haja entre animais humanos e não-humanos reciprocidade e relações de justiça, também são obrigados a assumir que não há reciprocidade, nesse sentido requerido, entre seres humanos "normais" e pessoas com impedimentos mentais graves. Ralws define a reciprocidade como uma relação entre cidadãos entendidos nos termos da concepção kantiana de pessoa. (NUSSBAUM, 2013, p. 166) 
Aquilo que é central, em Habermas, para a definição de um ideal de autonomia - e, portanto, para acentuar a possibilidade de tratamento diversos entre os indivíduos em termos de efetivo reconhecimento de exercício de liberdades -, a reciprocidade, é problemático em Nussbaum como pressuposto, justamente, de restrição a uma liberdade de agir em sociedade. E, nesses termos, Nussbaum parte de uma base de justiça social para efetuar a crítica ao que refere ser uma dualidade de mundos em Kant (NUSSBAUM, 2013, p. 165). Responde, em termos políticos, à construção filosófica da modernidade perfeccionista em termos de moralidade:

\begin{abstract}
Assim sendo, as pessoas com impedimentos e deficiências mentais representam um duplo desafio para a teoria de Rawls. A doutrina do contrato parece ser incapaz de acomodar suas necessidades por atenção social especial, em função da falta de produtividade e do custo social que todas as pessoas com impedimentos representam. Mas elas também são desqualificadas para a cidadania em um sentido mais profundo, porque não se conformam com um retrato bem idealizado da racionalidade moral que é usado para definir cidadãos de uma Sociedade Bem Ordenada. Como os animais não humanos, elas também não são consideradas capazes da reciprocidade do tipo requerido. E, mais uma vez, como os animais, terão "certamente algum tipo de proteção", mas não o status de cidadãs plenas. Novamente, a própria conclusão de Rawls parece apropriada: os dizemos que estas são questões de justiça, ou devemos dizer que a justiça como equidade não oferece uma explicação completa acerca da justiça social, e devemos imaginar o que precisaríamos alterar para fazer que a teoria avance. (NUSSBAUM, 2013, p. 168)
\end{abstract}

De certa forma, há razão em Nussbaum quando afirma que, para os teóricos da modernidade, há uma certa dificuldade em vencer a questão da autonomia e da reciprocidade no que se refere à capacidade e à definição de estruturas dogmáticas em relação ao tema da igualdade e da justiça social. Mas não há como afastar a compreensão de que igualmente há problemas em relação às definições clássicas de doutrinas da antiguidade quando se misturam argumentos políticos - das estruturas sociais da época - e filosóficos estritos. Assim, por exemplo, no enfrentamento do tema da escravidão por filósofos da antiguidade. Há, por consequência, que se efetuar temperamentos em face dos avanços da experiência empírica e do próprio desenvolvimento social. O que, contudo, não pode se traduzir, necessariamente, no abandono de estruturas normativas formais que garantam segurança jurídica para a correção de respostas adequadas às circunstâncias concretas de análise, principalmente em temas tão caros à personalidade do indivíduo, como a questão da capacidade.

A filosofia prática contemporânea, em certa medida, parte da preocupação em elucidar, do ponto de vista moral, que critérios devem ser adotados para analisar situações 
que possam enfrentar os temas do igual interesse de cada um e do igualmente bom para todos em sociedade. Isto passa a ser um problema contemporâneo permanente pelo fato de que, por mais que haja o convencimento de que as teorias deontológicas pós-Kant expliquem como as normas morais devem ser fundamentadas e aplicadas - e quanto a isso talvez não se tenha dúvidas em relação à construção da razão-prática, ainda que possam haver distinções dos pressupostos de base -, não haja suficiente convicção do porquê devem as pessoas serem morais. E, quanto a isso, como ressalta Habermas, "certamente a teoria moral paga um preço muito alto por dividir seu trabalho com uma ética especializada nas normas da autocompreensão existencial" (HABERMAS, 2004b, p. 7).

Para quem não parta, por definição, de um modelo de moral perfeccionista, uma resposta estratégica a tal tipo de indagação - saber por que devemos observar condutas morais apesar de tudo - talvez esteja fundada numa situação de risco. Na medida em que, seguindo Habermas, reconhece-se que os avanços tecnológicos passam a exigir uma nova "margem de decisão" (HABERMAS, 2004b, p. 18) inclusive quanto aos limites à geração de vida humana - portanto, com reflexos em todas as demais questões pertinentes às questões de personalidade -, corre-se um sério risco de estabelecimento de novos parâmetros à autocompreensão. Portanto, ou decide-se de forma autônoma, "segundo considerações normativas que se inserem na formação democrática da vontade" (HABERMAS, 2004b, p. 18), ou permite-se uma sujeição possível à arbitrariedade, "em função de preferências subjetivas, que serão satisfeitas pelo mercado" (HABERMAS, 2004b, p. 18).

A dupla dinâmica de enfoque em relação à dimensão de autonomia do indivíduo como individualidade e como intersubjetividade - aproxima a discussão filosófica do campo de análise da liberdade em termos jurídicos. Quando se fala em autonomia, se está, em verdade, discutindo questão mais ampla que a pressuposta num direito geral de liberdade pelo indivíduo, como visto em Habermas. Para quem parta de uma concepção moderna de liberdade, fundada a partir de um enfoque filosófico humanista, toda interpretação acerca do fenômeno da capacidade jurídica não dispensa, para a situação concreta, o exercício do teste transcendental de Kant por uma ética universal. Daí a pergunta: É possível generalizar a conduta de suprimir-se o conceito de discernimento da ideia de autonomia para a construção de novas categorias dogmáticas em termos de capacidade? O que se fazer frente à lacuna normativa proposta pelo Estatuto da Pessoa com Deficiência, em relação à capacidade jurídica, em termos de interpretação? 


\section{PARTE II: DISCERNIMENTO E CAPACIDADE.}

O que torna mais complicado enfrentar, na contemporaneidade, o tema da autonomia é justamente o fato de que nem sempre partimos de mesma definição acerca das condições de interação em sociedade. E aqui nem se fala de uma hipótese de ausência de espaço à construção do juízo, como em Hannah Arendt (1999), pelo reconhecimento da falta do espaço para o ato de pensar. Tal realidade encontra-se pressuposta. A questão discutida é quanto à própria extensão acerca de uma definição do conceito de autonomia para a construção de juízos morais ou mesmo de juízos eminentemente jurídicos, capazes de interferirem de forma significativa em conflitos complexos, como por exemplo, no campo da bioética, na definição de capacidades ou no recente debate sobre o direito dos animais nãohumanos - inclusive para o reconhecimento de capacidade própria.

Há quem compreenda, como Nussbaum, que a autonomia possa ser uma condição precária de "existência finita" (NUSSBAUM, 2013, p. 192) e que, portanto, apenas se veja fortalecida quando existente uma consciência - e, mais, uma condição de reconhecimento $a$ priori - de uma vulnerabilidade no corpo social. O que representa, de certa forma, um retorno ao pensamento antigo baseado em virtudes e restrições desde logo justificadas e fundadas numa justiça distributiva repaginada pela ideia de "cooperação social” (2013). Ou ainda, compreender, na linha de Ronald Dworkin (2014), que é possível distinguir fronteiras entre a boa vida e o bem viver, dimensionando ideais éticos distintos para a vida com dignidade e para o alcance de condições fáticas suficientes (na saúde, nos relacionamentos, nas circunstâncias econômicas) ao desenvolvimento de uma vida digna.

Mais recentemente, Michael Sandel (2013) igualmente propôs a discussão do tema a partir de situações de ética aplicada, em que discute, de forma crítica, hipóteses de "melhoramento genético" (2013, p. 13) - a partir da dualidade observada às descobertas genéticas, seja como promessa de melhora à saúde, seja como dilema de manipulação da natureza humana (2013, p. 19) - e de uma nova proposta de eugenia no mundo contemporâneo por uma ética sujeita a relativizações. A opção de Sandel, dadas às situações extremas de análise, é por uma ética que implique em ponderação frente aos casos apresentados, ainda que parta de uma concepção de autonomia quase sacra: "Ganharíamos mais cultivando uma valorização mais ampla da vida como dádiva que pede nossa reverência e restringe nosso uso" (SANDEL, 2013, p. 133).

Não é por acaso, por consequência, o retorno às virtudes e aos ideais antigos sobre 
o que deve ser contido, ainda que minimamente, na ideia do "bem". A preocupação é justamente com a força do argumento apresentado por autores como Peter Singer à base de uma filosofia utilitarista que ganha corpo numa visão mais ampla de interesse. Quando busca se tratar, de forma séria, de temas como a questão da capacidade, do aborto e da eutanásia, da igualdade entre espécies - e, portanto, não apenas entre humanos - pelo enfoque utilitarista, é sedutora a construção filosófica oferecida que permite vencer, pela ideia de interesse, qualquer fronteira de questões de justiça - principalmente em termos de igualdade - a envolver animais ou pessoas com determinadas incapacidades. Por outro lado, é extremamente preocupante, como aponta Nussbaum, partir de uma visão que "encoraje a produzir as melhores consequências gerais como ponto de partida correto para a justiça política" (2013, p. 417). Tal pressuposto, inclusive, seria o elemento que permitiria explicar, para Nussbaum, certa retração a priori na construção de uma concepção de autonomia:

Realizar uma pequena lista das capacidades centrais, como direitos fundamentais baseados na justiça, é um modo de posicionar-se acerca do conteúdo. Mas é também, principalmente, um modo de anunciar nossa contenção diante de pessoas com concepções abrangentes diferentes (NUSSBAUM, 2013, p. 419).

A questão, por consequência, é a de compreender em que medida se deve estabelecer limites a priori a um exercício de liberdade intersubjetiva e de que forma devem estar justificadas razões sérias à restrição de toda e qualquer liberdade ao mesmo tempo em que se possa potencializar a autonomia como um princípio ainda relevante à moral na sociedade contemporânea. Algo que escapa ao enfoque utilitarista, mesmo na concepção mais liberal de Peter Singer (2009), na medida em que o problema da justiça parte não de um foco central na análise de liberdades - e, portanto, com ausência de preocupação centrada no valor da autonomia - e sim na análise privilegiada de pressupostos de igualdade. E esta talvez seja a questão perversa em relação à construção utilitarista do argumento moral de fundo. Para alcançar-se uma pretensão estratégica de cunho liberal - e, assim, potencializar o melhor dos interesses a quem esteja diretamente relacionado num conflito, independentemente de juízos hipotéticos a priori -, a justificativa filosófica compreende uma premissa valorativa de cunho igualitário amplo, capaz de criar patamares abstratos e 
meramente formais de igualdade na mesma proporção em que gera um risco de destruição significativa à tradição humanista de construção de valores à existência humana.

Não por outro motivo poderia se questionar a edição recente do Estatuto da Pessoa com Deficiência (Lei $\mathrm{n}^{\mathrm{o}}$ 13.146/15) no Brasil, quando suprime, sob o pressuposto da igualdade de tratamento entre as pessoas, o texto do enunciado normativo do art. $3^{\circ}$ do Código Civil brasileiro, extirpando do Código Civil o critério do discernimento - e, portanto, da ideia de racionalidade - para a determinação da capacidade civil. Pela alteração de texto, onde antes se reconhecia incapacidade absoluta aos que, por enfermidade ou deficiência mental, não tivessem o necessário discernimento para a prática de atos da vida civil (art. $3^{\circ}$ ), hoje se compreende que descabida é qualquer descriminação normativa $a$ priori em razão das condições de intelecção do indivíduo, deixando o texto legal, portanto, de oferecer critérios suficientes para a aferição da real capacidade do indivíduo à manifestação livre e consciente da vontade. Onde antes havia discernimento, hoje há igualdade material pressuposta sem qualquer condição prévia de investigação suficiente sobre a efetiva autonomia da pessoa no exame do caso concreto. Não há, para o caso, como não reconhecer que possa se ter pressuposto, filosoficamente, a adoção de um enfoque eminentemente funcionalista em relação à concepção de autonomia para as questões que envolvem capacidade da pessoa, na medida em que prestigiada uma ideia de igualdade formal e material entre os indivíduos ampla, em detrimento a uma ponderação necessária acerca de critérios claros para o estabelecimento das condições quanto à possibilidade de expressão da vontade própria.

Mas há ainda um perigo mais imediato em relação à interpretação da supressão da expressão discernimento da definição de capacidade aos indivíduos: a possibilidade de que, na ausência de um critério previamente orientador da interpretação, esteja aberta a oportunidade para a discricionariedade irrestrita por parte do intérprete judicial. Tal dedução é possível pelo fato de que a Lei $\mathrm{n}^{\circ} 13.146 / 15$ ao prever a revogação expressa do reconhecimento de incapacidade a quem, por enfermidade ou deficiência mental, não tenha “o necessário discernimento" para a prática de atos civis, deixa de estabelecer qualquer critério científico suficiente à tomada de decisão, quando necessário, para a correta apreensão da manifestação livre de vontade. Em lugar disso, prevê um sistema de tomada de "decisão apoiada", em que estabelecida a possibilidade de expressão da vontade por meio de terceiros a quem é confiada uma espécie de curatela mitigada sob supervisão judicial. A 
questão é que não há o estabelecimento abstrato - ao contrário do anteriormente previsto no Código Civil - de quando tal circunstância deva ser observada em concreto, justamente porque ausente qualquer linha divisória à compreensão do efetivo comprometimento da vontade, principalmente quando envolvidos interesses de terceiros ou situações de proteção à personalidade da pessoa com deficiência.

Veja-se que a ideia de discernimento anteriormente consagrada na dogmática jurídica - ainda que passível de interpretações com certa dificuldade - havia atingido descarga de argumentação suficiente para a construção do conceito de autonomia, permitindo equilíbrio entre a efetiva possibilidade de expressão da vontade e a interna disposição quanto ao interesse efetivo à manifestação desta vontade. E aqui a ideia de descarga que se reconhece é em relação ao alcance argumentativo antes visto na construção do conceito de autonomia por meio da ideia de discernimento. Significa, como acentua Alexy (2012, p. 257), que, não havendo uma razão especial, torna-se desnecessário ao intérprete comprovar o que já se tem como consenso em relação à justificação alcançada por determinado enunciado dogmático. Ao mesmo tempo em que tal função reforça um sentido de universalidade pretendido ao enunciado normativo, permite que se reconheça uma relevância essencial ao consenso, alcançado pela interpretação, acerca do enunciado dogmático em discussão.

A atividade de descarga autoriza que se visualize aparente rigidez em relação a uma fundamentação dogmática, porque mantém estável a força semântica de um enunciado normativo em relação a uma situação universal. Não impede, porém, que seja proposto um novo consenso em relação ao mesmo enunciado na medida em que identificadas outras funções específicas dos enunciados dogmáticos, como a de progresso. Mas impõe, em medida assemelhada, a exigência de uma carga argumentativa de mesma relevância para o estabelecimento do consenso - e isto é essencial A ausência de uma função de descarga, própria à dogmática, não justificaria, mas poderia tornar facilitada a tendência a um decisionismo, permitindo a complementação de enunciados normativos exclusivamente por argumentos empíricos - que, por si só, não se apresentariam suficientes à construção de uma razão prática. Dito de outra forma, como acentua Sérgio José Porto, sem a opção pelo estabelecimento de uma precisão em relação à hipótese legal, "corre-se o risco de tomar o lugar de numerosos institutos jurídicos" (PORTO, 1995, p. 15).

O que se busca resgatar para a interpretação normativa, com a edição do Estatuto da Pessoa com Deficiência, é a autonomia que é vista como determinante para a interpretação de qualquer ato jurídico e que, portanto, reflete a situação de capacidade prevista para efeito 
de uma interpretação jurídica como a orientada no art. 112 do CC brasileiro em relação aos atos da vida civil. Ou seja, no sentido de que "nas declarações de vontade se atenderá mais à intenção nelas consubstanciadas do que ao sentido literal da linguagem" (art. 112 do CC brasileiro). Daí a dificuldade de compatibilização do que hoje é previsto de forma geral em relação a todos os indivíduos - e que reflete, inclusive, as situações de proteção à vulnerabilidade construídas historicamente - com a situação nova prevista no Estatuto das Pessoas com Deficiência, a afastar justamente o critério do discernimento para efeito de caracterização de uma situação de vulnerabilidade extrema, como a situação pressuposta a quem esteja em situação reconhecida de "impedimento de longo prazo de natureza física, mental, intelectual ou sensorial, o qual, em interação com uma ou mais barreiras, pode obstruir sua participação plena e efetiva na sociedade em igualdade de condições com as demais pessoas"(art. $2^{\circ}$ da Lei $\left.n^{\circ} 13.146 / 15\right)$.

O receio é de que a orientação hoje promovida à interpretação em termos de capacidade, quando se trate de pessoa com deficiência, reste condicionada a mitigar a proteção jurídica prevista e reconhecida pela ideia de discernimento. Tal preocupação é fundada, justamente, na revogação expressa ao inc. II do art. $3^{\circ}$ do CC brasileiro, aliada à ausência de previsão específica de critério substitutivo à interpretação, na medida em que limitada a Lei $n^{\circ} 13.146 / 15$ a oferecer, para a orientação da discricionariedade judicial, a adoção de um procedimento de "tomada de decisão apoiada" - ou, no máximo, de espécie de instituto de tutela enfraquecido - em que considerada a opinião de terceiros que sejam da confiança da pessoa com deficiência e nomeados para tal finalidade. Ou, na hipótese de ocorrência de conflito de interesses entre os terceiros a quem confiada a tomada de decisão, a necessidade de estabelecimento de um processo específico de avaliação da decisão tomada em concreto por meio de equipe de técnicos, novamente sem o oferecimento de um critério suficiente à identificação da efetiva dificuldade de manifestação livre da vontade por parte do indivíduo prejudicado na compreensão cognitiva da situação concreta de análise. E mais: sem a devida responsabilização dos terceiros que acabem efetivamente tomando decisões no interesse da pessoa com deficiência.

O que se acentua, por consequência, é que, embora o Estatuto da Pessoa com Deficiência tenha permitido colocar em destaque situação de promoção de igualdade formal a pessoas com deficiência, deixou de considerar, especialmente àqueles que apresentam déficit cognitivo relevante para a tomada de decisões em relação a atos da vida civil, critério consagrado na dogmática para fins de proteção ao livre desenvolvimento da personalidade como na hipótese do conceito de discernimento -, gerando, ao contrário do pretendido, 
insegurança jurídica. Uma situação de lacuna normativa que, caso não corrigida pela interpretação possível às cortes judiciais, permitirá, inclusive, desproporção de interpretação em relação a outras situações de vulnerabilidade que recebem proteção específica por meio de estatutos jurídicos próprios conforme a posição jurídica considerada - como na hipótese de idosos, crianças e adolescentes, consumidores.

\section{CONCLUSÕES}

Mesmo partindo-se de concepções distintas sobre uma definição ao conceito de autonomia, percebe-se o quanto pode ser temeroso alterar-se estruturas dogmáticas - como em relação ao instituto da capacidade civil - a partir de uma análise exclusivamente empírica ou ideológica. O debate proposto neste artigo buscou discutir o conceito de autonomia para a construção de juízos morais ou mesmo de juízos eminentemente jurídicos, capazes de interferirem de forma significativa em conflitos complexos, como no campo da bioética ou na definição de capacidades pela recente vigência da Lei $n^{\circ} 13.146 / 15$. Seja a partir da compreensão de autores como Martha Nussbaum - para quem a autonomia é uma condição precária de "existência finita" (NUSSBAUM, 2013, p. 192) - ou de Ronald Dworkin (2014) - a quem é possível distinguir fronteiras entre a boa vida e o bem viver, dimensionando ideais éticos distintos para a vida com dignidade e para o alcance de condições fáticas suficientes ao desenvolvimento de uma vida digna -, verifica-se uma certa tendência ao retorno às virtudes e aos ideais antigos sobre o que deve ser contido, ainda que minimamente, na ideia do "bem". A preocupação é a de marcar oposição a autores, como Peter Singer, que desenvolvem, à base de uma filosofia utilitarista, uma visão mais ampla de interesse.

A questão, por consequência, é a de compreender em que medida se deve estabelecer limites a priori a um exercício de liberdade intersubjetiva e de que forma devem estar justificadas razões sérias à restrição de toda e qualquer liberdade ao mesmo tempo em que se possa potencializar a autonomia como um princípio ainda relevante à moral na sociedade contemporânea. Daí o questionamento à edição recente do Estatuto da Pessoa com Deficiência (Lei ${ }^{\circ}$ 13.146/15) no Brasil, que suprime, sob o pressuposto da igualdade de tratamento entre as pessoas, o texto do enunciado normativo do art. $3^{\circ}$ do Código Civil brasileiro, extirpando do Código Civil o critério do discernimento para a determinação da capacidade civil. Onde antes havia discernimento, hoje há igualdade material pressuposta sem qualquer condição prévia de investigação suficiente sobre a efetiva autonomia da pessoa 
no exame do caso concreto. Não há, para o caso, como não reconhecer que possa se ter pressuposto, filosoficamente, a adoção de um enfoque eminentemente funcionalista em relação à concepção de autonomia para as questões que envolvem capacidade da pessoa, na medida em que prestigiada uma ideia de igualdade formal e material entre os indivíduos ampla, em detrimento a uma ponderação necessária acerca de critérios claros para o estabelecimento das condições quanto à possibilidade de expressão da vontade própria.

Para quem siga uma compreensão filosófica pelo discurso jurídico, a partir do pensamento de Jürgen Habermas, em que a racionalidade assume papel relevante para a construção da argumentação em concreto, a autonomia é um conceito que pressupõe sempre intersubjetividade, determinando-se por máximas aprovadas pelo teste da universalização. Nessa perspectiva, é fundamental que se resgate, para a interpretação normativa, o conceito de discernimento antes consagrado pela dogmática jurídica, justamente em face do papel de descarga pressuposto para a promoção ao livre desenvolvimento da personalidade. Uma situação de lacuna normativa constatada que, caso não corrigida, permitirá desproporção de interpretação em relação a outras situações de vulnerabilidade que recebem proteção específica por meio de estatutos jurídicos próprios.

\section{REFERÊNCIAS BIBLIOGRÁFICAS}

ALEXY, Robert. Teoría de La argumentación jurídica. Madrid: Centro de Estudios Políticos y Constitucionales, 2012.

. Teoría de los derechos fundamentales. 2. ed. Madrid: CEPC, 2001.

ARENDT, Hannah. Eichmann em Jerusalém. Um relato sobre a banalidade do mal. São Paulo: Companhia das Letras, 1999.

DWORKIN, Ronald. A raposa e o porco-espinho. Justiça e valor. São Paulo: Martins Fontes, 2014.

FERRY, LUC. A Nova Ordem Ecológica: a árvore, o animal, o homem. Rio de Janeiro: Editora Difel, 2009.

; VINCENT, Jean-Didier. O que é o Ser Humano. Sobre os princípios fundamentais da filosofia e da biologia. Petrópolis: Editora Vozes, 2011.

HABERMAS, Jürgen. A ética da discussão e a questão da verdade. São Paulo: Martins Fontes, 2004.

Comentários à ética do discurso. Lisboa: Piaget, 1991.

O futuro da natureza humana. São Paulo: Martins Fontes, 2004. 
NUSSBAUM, Martha. Fronteiras da justiça. Deficiência, nacionalidade, pertencimento à espécie. São Paulo: Martins Fontes, 2013.

PORTO, Sérgio José. A responsabilidade civil por difamação no direito inglês. Porto Alegre: Livraria do Advogado, 1995.

ROUANET, Sérgio Paulo. Mal-estar na modernidade. São Paulo: Companhia das Letras, 2003.

SINGER, Peter. Ética práctica. Madrid: Akal, 2009. 